\title{
MIMES, THAUMATURGY, AND THE THEATRE
}

Leontius of Naples in his Life of Symeon Salos, written around the middle of the seventh century A.D., describes an encounter that the subject of the Life, the holy fool Symeon, had had with some mimes in the theatre in Emesa: ${ }^{1}$

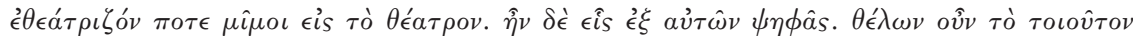

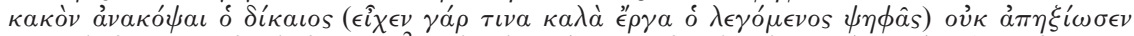

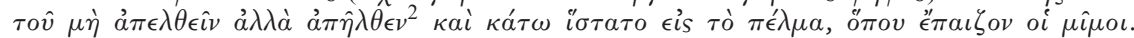

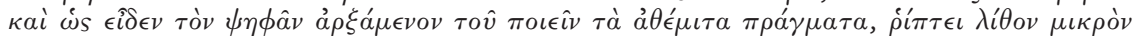

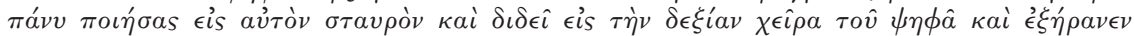

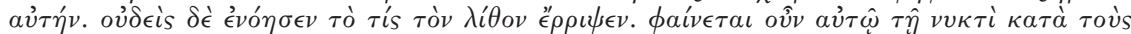

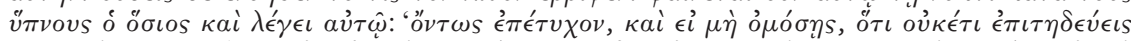

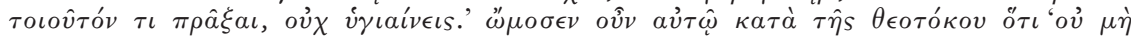

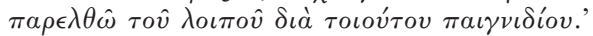

(150 Rydén)

Once some mimes were putting on a show in the theatre. One of their number was a conjuror with pebbles. The righteous one, since he wished to exterminate that evil-for the so-called pebble-conjuror had some good deeds to his credit — did not think it right to depart, but he did not depart and took up a stance below on the floor of the theatre, ${ }^{3}$ where the mimes were performing. When he saw the conjuror beginning to carry out his lawless deeds, ${ }^{4}$ he threw a very small stone, after making the Sign of the Cross on it, and struck the right hand of the man with it, causing it to wither. No one noticed that someone had thrown the stone. The holy one appeared during the night to the conjuror when he was sleeping and said to him: 'I truly have hit my mark. Unless you swear not to follow such a practice, you will not get well.' The conjuror, accordingly, swore to him by the Mother of God: 'I shall not in future have anything to do with such a trick. ${ }^{5}$

A $\psi \eta \phi \hat{\alpha}$ s is a type of illusionist whose ancestry stretches back as far as the early fourth century B.C., if not further. In earlier times, he was more often known as a

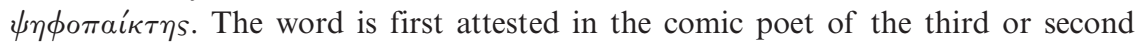
century B.C., Eudoxus (fr. 1 K.-A.), although Lysias uses a denominative verb $\psi \eta \phi о \pi \alpha \iota \kappa \tau \epsilon \hat{\imath} \nu$ (fr. 17). He may also be called a $\psi \eta \phi о \kappa \lambda \epsilon ́ \pi \tau \eta s$ or a $\psi \eta \phi o \lambda o ́ \gamma o s$ or a $\psi \eta \phi \iota \sigma \tau \eta{ }^{\prime} .{ }^{6}$ According to Athenaeus, the people of Hestiaea or Oreos erected a bronze

${ }^{1}$ Derek Krueger, Symeon the Holy Fool: Leontius' Life and the Late Antique City (Berkeley, Los Angeles and London, 1996), 21-2, while conceding that the episodes in Emesa are nonspecific in their reference, maintains that the atmosphere reflected in them is that of the relative prosperity of Cyprus in the seventh century rather than Emesa in the sixth. But it is far from certain that the Life can safely be used as evidence of conditions in the Cyprus of Leontius' day.

${ }^{2}$ The $\dot{\alpha} \pi \hat{\eta} \lambda \theta \epsilon \nu$ that Rydén and Festugière (A. J. Festugière en collaboration avec Lennart Rydén, Vie de Syméon le Fou et Vie de Jean de Chypre [Paris, 1974]) print makes no sense, since clearly Symeon did not go away from the theatre. It looks as though either there has been dittography and a verb meaning 'to approach or enter' has been replaced or ovं $\kappa$ has fallen out.

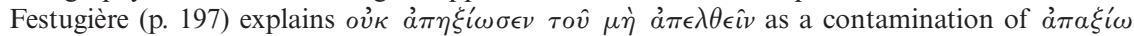
$\tau \iota \nu o ́ s$ and $\alpha \dot{\alpha} \alpha \xi^{\prime} i \omega \mu \grave{\eta}+$ infinitive.

${ }^{3}$ Both Festugière (n. 2), 138 and Krueger (n. 1), 155 translate i" $\sigma \tau \alpha \tau o$ by 'sit'.

${ }^{4}$ Krueger (n. 1), 155 in his translation takes it to be Symeon who performs the wicked deeds.

${ }^{5}$ For expressions of the form $\pi \alpha \rho \epsilon \lambda \theta \epsilon \hat{\imath} v \delta \iota \alpha$ ' $\tau \iota \nu o s$ meaning 'to engage in a practice', see L.Rydén, Bemerkungen zum Leben des heiligen Narren Symeon von Leontios von Neapolis, Studia Graeca Upsaliensia 6 (Uppsala, 1970), 100-1.

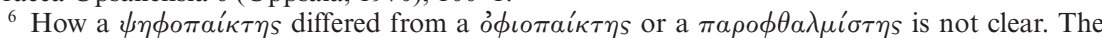
Hermeneumata Ensiedlensia in its list of theatrical terms glosses the former term by praestigiator

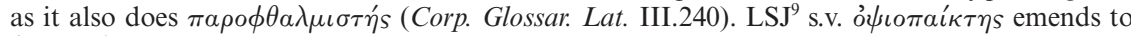

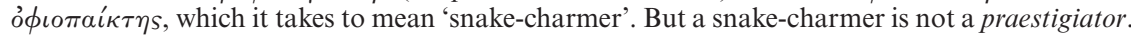


statue of the $\psi \eta \phi о к \lambda \epsilon ́ \pi \tau \eta s$, Theodorus, in the theatre, showing him controlling a pebble (1.19b). The term $\psi \eta \phi \iota \tau \eta^{\prime} s$ is attested in a Byzantine astrological text that draws on and paraphrases some paragraphs of Vettius Valens on the influence of the star Mercury. ${ }^{7}$ There, $\psi \eta \phi \iota \sigma \tau \eta^{\prime}$ is a rendering of the periphrasis in Vettius for a $\psi \eta \phi о \pi \alpha i \kappa \tau \eta s:$

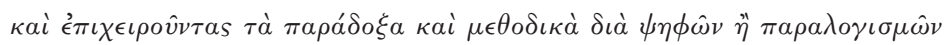

Those attempting to create wonders and tricks through pebbles or deceptive devices.

$\psi \eta \phi \iota \sigma \tau \eta$ s also occurs in a glossary, the Hermeneumata Montepessulana, as the equivalent of the Late Latin term for one who does tricks with pebbles, a cauculator. ${ }^{8}$

$\mathrm{LSJ}^{9}$ gives as the meaning of $\psi \eta \phi о \pi \alpha i \kappa \tau \eta s^{\prime}$ 'one who juggles with pebbles'. The same authority says that a $\psi \eta \phi \hat{\alpha} s$ is a 'juggler'. Neither a $\psi \eta \phi о \pi \alpha i \kappa \tau \eta s$ nor a $\psi \eta \phi \hat{\alpha} s$ is a juggler, but someone who tricks spectators, by sleight of hand, into believing that they are seeing what they are not seeing; that is to say, a conjuror or prestidigitator. ${ }^{10} \mathrm{In}$ the case of the word $\psi \eta \phi о \pi \alpha i \kappa \tau \eta s$ that emerges unequivocally from the comparison made by Sextus Empiricus of orators who by their roguery blind the minds of judges and steal their votes to $\psi \eta \phi о \pi \alpha \hat{\imath} \kappa \tau \alpha \iota$ who deceive the eyes of spectators by their sleight of hand:

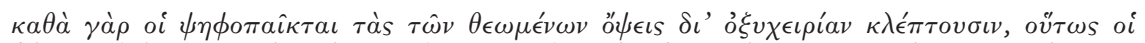

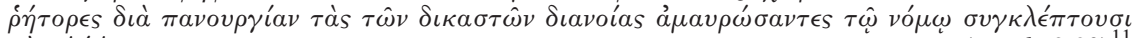

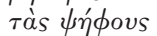

$\left(\right.$ Math. 2.39) ${ }^{11}$

$\psi \eta \phi a ́ \delta \epsilon s$ also deceived the senses by leading eyes astray. Thus Athanasius can compare the Antichrist, giving a glimpse here and glimpse there of gold or silver and so leading the eyes of men astray, to the actions of $\psi \eta \phi \alpha \dot{\delta} \epsilon s$ :

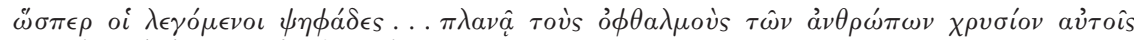

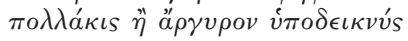

(Q. Ant. $125 P G$ 28.677)

Deception and trickery are, accordingly, at the heart of what it was to be a $\psi \eta \phi о \pi \alpha i \kappa \tau \eta s$ or a $\psi \eta \phi \hat{\alpha} s$. To judge from his name, he will have used pebbles in performing his tricks. Seneca clearly refers to such specialized conjurors when he speaks of the pleasure that being fooled by the cups and the pebbles of conjurors gives him (sic ista sine noxa decipiunt quomodo praestigiatorum acetabula et calculi, in quibus me fallacia ipsa delectat, Ep. 45.8). Exactly what the deception practised by such conjurors lay in is not altogether clear. The testimony of Artemidorus suggests that it

Louis Robert, Opera Minora Selecta II (Amsterdam, 1969), 895 with n. 2 suggests that the man

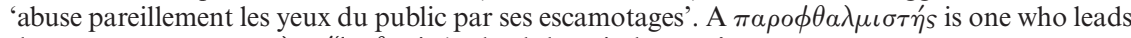
the eyes astray as $\pi \alpha \rho a \lambda o \gamma$ i $\epsilon \sigma \theta \alpha \iota$ is 'to lead the mind astray'.

${ }^{7}$ Cod. Venet. Marc. Gr. 224ff. 184-94 published by Wilhelm Kroll, CCAG 2 159-80, republished as Vett. Val. Appendix I 388.1 Pingree.

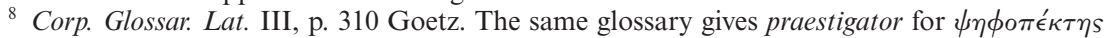
(Corp. Glossar. Lat. III, p. 310 Goetz). The Hermeneumata Monacensia glosses psiphopectis by cauculator and psephas by cauculos (Corp. Glossar. Lat. II, 198 Goetz).

${ }^{9} \mathrm{LSJ}^{9}$ and Lampe s.v. put an acute on the ultimate, but the word follows the same pattern as other terms for occupations in Late Greek ending in - $\hat{\alpha} s$ and takes a perispomenon on the ultimate. So Festugière (n. 2), 196-7. The correct accent is given at CCAG 7.118, 8.3.110, 8.4.217.

${ }^{10}$ So H. Blümner, 'Fahrende Volk im Altertum', Sitz. München. (1918), 19; Franz Cumont, L'Égypte des astrologues (Bruxelles, 1938), 85, n. 4; Robert (n. 6), 859. Festugière (n. 2), 138 calls him a 'un jongleur' and Lennart Rydén, 'The holy fool', in The Byzantine Saint: The XIVth Spring Symposium of Byzantine Studies, Studies Supplementary to Sobornost 5 (London, 1981), 109 'a juggler'. 
consisted in being able to put before the spectators more or less pebbles than they imagined they had seen before:

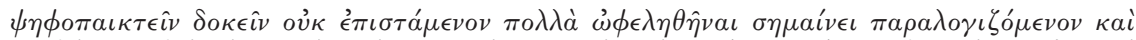

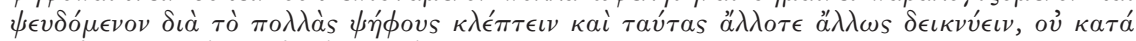

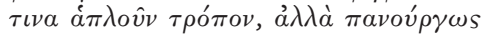

To dream that one is a $\psi \eta \phi о \pi \alpha i k \tau \eta s$ for someone who does not know the craft signifies great benefits gained by cheating and deceit, since the $\psi \eta \phi о \pi \alpha^{i} \kappa \tau \eta \xi s$ surreptitiously abstracts many pebbles and displays them again at another moment, not in a straightforward manner, but in that of a rogue. ${ }^{12}$

The pebbles were not only put in front of the spectators, perhaps on a table, but might appear in the parted lips of the conjuror. ${ }^{13}$ Similarly, the prestidigitator whose speciality was thimble-rigging, which is to say doing conjuring-tricks with peas or pebbles placed under small cups, would display pebbles under a cup and then cause them to vanish when next he raised the cup, only to make them appear in his mouth; he might then swallow them and pull them out of the ear, nose or throat of spectators (Alciphr. 3.20). ${ }^{14}$

We may turn now to the question of what a conjuror or prestidigitator was doing performing as a mime or performing amongst mimes. There are other indications that such illusionists were to be found working alongside or amongst mimes. In the astrological texts, $\psi \eta \phi a ́ \delta \epsilon s$ tend to be mentioned in the same breath as $\mu \hat{\imath} \mu о \iota$ ( $C C A G$ $7.118,8.3 .110,8.4 .217)$. Vettius Valens says that Mercury produces those trying to create wonders or tricks by means of pebbles and illusions and $i \sigma \chi v \rho о \pi \alpha \hat{\imath} \kappa \tau \alpha \iota$ or $\mu \iota \mu \omega \delta o i ́(1.1 .39) .{ }^{15} \psi \eta \phi о \pi \alpha \hat{\imath} \kappa \tau \alpha \iota$ and $\mu \hat{\imath} \mu о \iota$ were obviously associated in men's minds, presumably because they performed together.

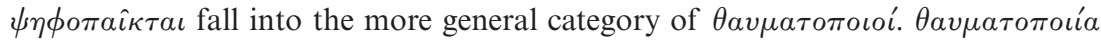
encompasses conjuring, acrobatics, juggling, and marionette-shows or, in other words, any kind of performance that produced baffled amazement in spectators. From the fourth century B.C. on $\theta \alpha v \mu a \tau o \pi$ oıoi are to be found performing alongside mimes

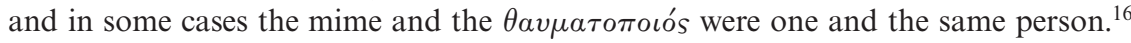
There were also dancers who danced mime-like dances who doubled as $\theta \alpha v \mu \alpha \tau o \pi$ oıoí. The earliest and best-known instance of such a performer is the ó $\rho \chi \gamma \sigma \rho i$ í in Xenophon's Symposium: at the end of the symposium she plays the role of Ariadne as bride of Dionysus in a performance that encompasses music, dance and speech $(9.2-5),{ }^{17}$

${ }^{11}$ Cf. Pyr. 2.250; Artem. 3.55; Stob. Flor. 2.2.11. Dosith. Gramm. 71 glosses $\psi \eta \phi о \pi \alpha \iota \kappa \tau \hat{\omega}$ by praestigior.

${ }^{12}$ The comparison made by Athanasius of the Antichrist's giving a glimpse ( $\left.\dot{v} \pi \circ \delta \epsilon \iota \kappa v v v_{S}\right)$ of gold and silver and leading men's eyes astray to the action of a $\psi \eta \phi \hat{\alpha} s$ points to the same kind oftrick (Q. Ant. 125 PG 28.677).

${ }^{13}$ Front. Aur. 3: alter autem oleas suas in altum iaciat, ore aperto excipiat, exceptas ut calculos praestrigiator primoribus labris ostentet.

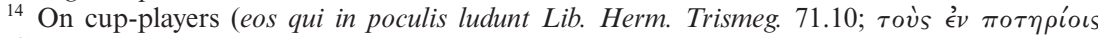

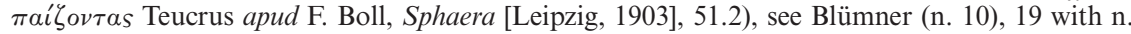
138, Cumont (n. 10), 85, n. 4. On the i $\mu \alpha \nu \tau \in \lambda_{\iota \kappa} \tau \eta^{\prime} s$, who challenged spectators to place a stick in a twisted leather thong that will not shake loose when the thong is unwound, see D'Arcy

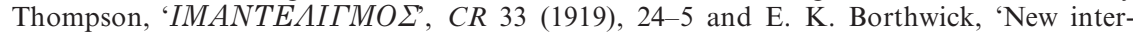
pretations of Aristophanes' Frogs 1249-1328', Phoenix 48 (1994), 23-6.

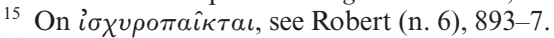

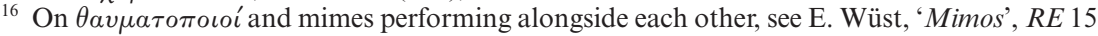
(1932), 1736-7.

${ }^{17}$ Bernhard Huss, Xenophons Symposion: Ein Kommentar (Stuttgart and Leipzig, 1999), 440 


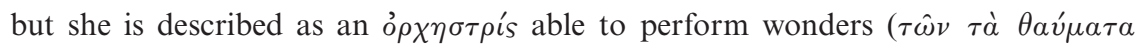
$\delta v \nu \alpha \mu \epsilon \in v \omega \nu \pi o \iota \epsilon \hat{\imath \nu} 2.1$ ). She lives up to that billing and puts on a performance of both juggling and acrobatics $(2.8,11)$. The exponent of the Italian mime, Nymphodorus,

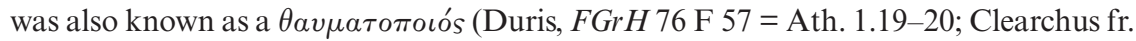
93 Wehrli = Ath. 10.452-3) ${ }^{18}$ Another exponent of the Italian mime, Ischomachus, also a figure from the fourth century B.C., is said, once he had become well-known, to have acted his mimes amongst wonder-working routines ( $\dot{\omega}_{S} \delta \dot{\epsilon} \epsilon \dot{v} \delta o \kappa \iota \mu \epsilon \hat{\imath}, \mu \epsilon \tau \alpha \beta \dot{\alpha} s$

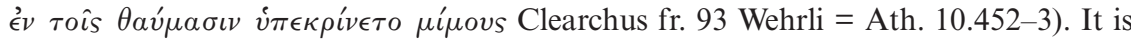

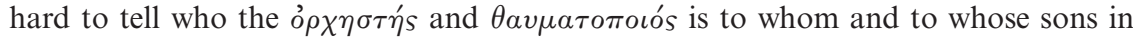
Roman times the Delphians granted citizenship and membership of the council (FD

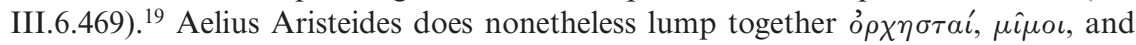

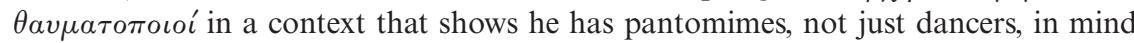
(Or. 50.414, Dindorf II, 567).

The evidence, such as it is, does not allow us to say whether Nymphodorus

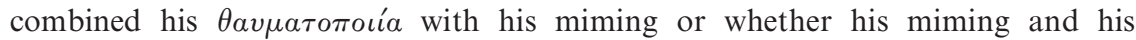
$\theta \alpha v \mu \alpha \tau о \pi о i ́ a$ were separate and distinct performances as they are in the case of the

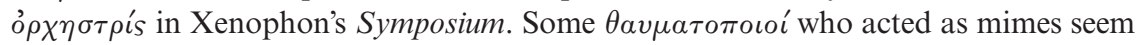
to have performed conjuring tricks that were an integral part of their act. The Atthidographer Phanodemus tells of a Locrian called Diopeithes who appeared in Thebes with bladders of milk and wine that he had attached to his person; he then squeezed them, saying that he was drawing the liquids from his mouth (FGrH $325 \mathrm{~F} 9$ $=$ Ath. 10.20a). Athenaeus, who cites Phanodemus here, goes on to say that the

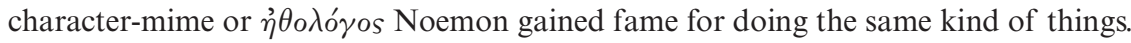
It is by no means clear whether Athenaeus is still drawing on Phanodemus, but it does rather sound as though Diopeithes was like Noemon a mime and that he pretended in performing as a mime to produce water and wine from his mouth.

$\psi \eta \phi о \pi \alpha \hat{\imath} \kappa \tau \alpha \iota$ undoubtedly performed in the theatre. The citizens of Oreos who set up in the theatre of their city a bronze statue of Theodorus in his role as $\psi \eta \phi о к \lambda \epsilon \epsilon \tau \eta S$ presumably put the statue in that location, because Theodorus had performed in their theatre (Ath. 1.19b). From the fourth century A.D. there is the statement of Eustathius of Antioch that $\psi \eta \phi о \pi \alpha \hat{\imath} \kappa \tau \alpha \iota$ are capable of performing many more and much greater feats in theatres than those on which sorcerers pride themselves (Engast. 9.10 Klostermann). But not all of them will have had the privilege of performing in a theatre. Those who did so were the stars. Others were ó $\chi \lambda \alpha \gamma \omega \gamma$ i or circulatores, which is to say persons who performed in the circle that gathered around them in a marketplace or at a crossroads, where they collected money from the spectators, before moving on to another location or town. Vettius Valens, after mentioning $\psi \eta \phi о \pi \alpha \hat{\imath} \kappa \tau \alpha \iota$ and $i \sigma \chi v \rho о \pi \alpha \hat{\imath} \kappa \tau \alpha \iota$ and $\mu \iota \mu \omega \delta o \iota$, goes on to speak of those making their living from public exhibitions and from wandering, vagabondage and from no settled exist-

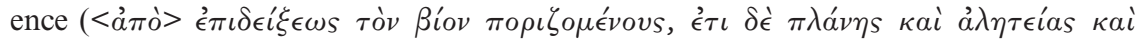

on 9.2-7 classifies the performance as a species of mime, dismissing the attempts of others to treat it either as straight mime or pantomime as pointless.

${ }_{18}$ For the identification, see H. Reich, Der Mimus (Berlin, 1903), 223.

${ }^{19}$ L. Robert, 'Epigraphica', REG 42 (1929), 435-6 = Opera Minora Selecta I (Amsterdam, 1969), 23-4 and 'Pantomimen im griechischen Orient', Hermes 65 (1930), 111 = Opera Minora Selecta I.659 is convinced, because two other pantomimes in inscriptions from Delphi are

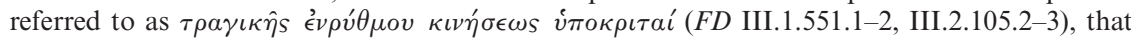
the man is not a pantomime, but a dancer of low status of the same order as the dancers known

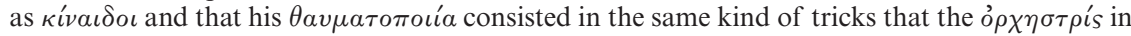
Xenophon's Symposium performed. This is a little too dogmatic. If he was a dancer of so low a status, the honours bestowed not only on him but on his sons are somewhat surprising. 


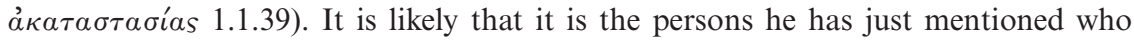
prompt him to speak of those living off the shows they put on and travelling as vagabonds from place to place. The collection of astrological poems that purport to be the work of Manetho, but in fact belong to the High Empire, describes $\psi \eta \phi о \pi \alpha \hat{\imath} \kappa \tau \alpha \iota$ doing just that in language that echoes that of Vettius:

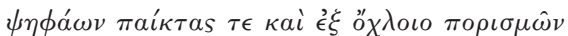

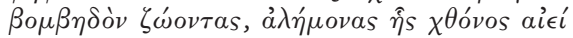

Players of pebbles, living like buzzing bees (i.e. moving from spot to spot) off what the crowd provides, wanderers always over the earth. ${ }^{20}$

Mimes and $\theta \alpha v \mu \alpha \tau o \pi$ o o i put on shows at symposia in private houses, at crossroads and in market-places, wherever a crowd might gather about them, and in the theatre. All of these venues provided a more or less suitable setting for the plays that the mimes performed, for displays of juggling and acrobatics and for such conjuring trick as a fire blazing up apparently spontaneously. ${ }^{21}$ But for $\psi \eta \phi о \pi \alpha \hat{\imath} \kappa \tau \alpha \iota$ the stage of a theatre is hardly an appropriate place of performance; the spectators need to be able to see and count the pebbles with which the $\psi \eta \phi о \pi \alpha i \kappa \tau \eta s$ performs his tricks. That may very well be the reason why Symeon stands below on the floor $\left(\pi \epsilon \epsilon^{\prime} \mu \alpha\right)$ of the theatre, where the mimes put on their show. ${ }^{22}$ Furthermore, unless Leontius is writing very loosely, Symeon does not take a seat, but stands during the performance.

A letter of Alciphron offers another instance of a conjuror performing in what looks to be the orchestra of a theatre. He does so in front of a group of spectators, at least some of whom are standing. The standing spectators in this case are active participants in the show. The writer purports to be a simple countryman who has gone to town to sell his produce and who while there had been taken to the theatre, where he had seen a thimble-rigger perform. From the fine seat he enjoyed the man had seen the

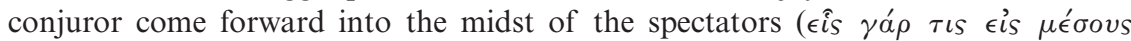
$\pi \alpha \rho \epsilon \lambda \theta \dot{\omega} \nu)$, where he had set up a tripod on which he had placed three small cups with which he had covered small white round pebbles; he had then shown all of them below one of the cups, only to make all of them disappear from that location and appear out of his mouth; his next move was to swallow them and then bring forward those

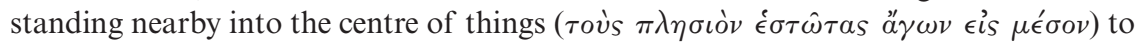
pull a pebble out of the nose of one, another out of someone's ear and yet another out of the gullet of a third, only to make them all disappear again (3.20). It is hard to see where the conjuror can be but in the orchestra of the theatre. Alciphron, it is to be imagined, describes a reality that he himself knows and is not drawing on an account of what went on in the theatre in Athens in the fourth century B.C. ${ }^{23}$

\section{University of Illinois at Chicago \\ M. W. DICKIE}

20 A. Koechly in Poetae Bucolici et Didactici (Paris, 1862) translates: calculorum lusores atque ex vulgi quaestibus susurratim viventes, erroneos suae terrae semper. Bees do not whisper, but buzz $(\beta o \mu \beta \epsilon \hat{\imath})$

${ }_{21}$ Ath. $1.19 \mathrm{e}$ credits the $\theta \alpha v \mu \alpha \tau o \pi$ oı́s Cratisthenes of Phlius with this trick.

${ }^{22}$ It is true that $\theta \epsilon^{\prime} \alpha \tau \rho o \nu$ may be used generally to designate a stadion, an amphitheatre, or a hippodrome, but in the absence of other markers the presumption must be that by $\theta \epsilon^{\prime} \alpha \tau \rho o \nu$ Leontius means a theatre. Reich thought that by $\pi \epsilon^{\prime} \lambda \mu \alpha$ Leontius had in mind the breast-high platform on which what he calls jugglers customarily performed. John Malalas, quoting the historian Charax who had said the hippodrome represented the cosmos, provides the appropriate parallel: he says that the $\pi \epsilon \lambda_{\mu \alpha}$ of the hippodrome signified the whole earth (Chron. 7.175). The $\pi \epsilon^{\prime} \lambda \mu \alpha$ is then the floor or orchestra of the theatre.

${ }_{23}$ I am indebted to David Bain and W. J. Slater for their criticisms and corrections of an earlier draft of the article. 